\title{
EDUCAÇÃO PERMANENTE NO CONTEXTO HOSPITALAR: A EXPERIÊNCIA QUE RESSIGNIFICA O CUIDADO EM ENFERMAGEM
}

\author{
PERMANENT EDUCATION IN THE HOSPITAL CONTEXT:THE EXPERIENCE THAT BRINGS \\ NEW MEANING TO NURSING CARE
}

\section{EDUCACIÓN PERMANENTE EN EL CONTEXTO HOSPITALARIO: LA EXPERIENCIA QUE RESIGNIFICA EL CUIDADO EN ENFERMERÍA}

\author{
Giovana Ely Flores ${ }^{1}$ \\ Dora Lúcia Leidens de Oliveira ${ }^{2}$ \\ Denise Antunes de Azambuja Zocche ${ }^{3}$
}

Resumo O artigo aborda o processo de formação vivenciado por enfermeiras educadoras no contexto hospitalar, na perspectiva da educação permanente em saúde, com destaques para as experiências que constituíram esse processo, os sentidos dessa formação e as mudanças decorridas no desenvolvimento do cuidado de enfermagem com base nas aprendizagens significativas. Tratou-se de estudo qualitativo exploratório-descritivo, desenvolvido por meio de grupos focais com sete enfermeiras que atuavam no Programa de Educação Permanente em Enfermagem num hospital universitário, em Porto Alegre, no estado do Rio Grande do Sul, em 2010, à luz dos pressupostos da Política Nacional de Educação Permanente em Saúde. A análise de conteúdo, do tipo temático, foi realizada utilizando-se o software NVivo 8.0 para organização e categorização dos dados obtidos. Os resultados mostraram que a participação das enfermeiras no programa resultou em abertura para diversas mudanças no seu processo de trabalho e na modelagem de ensino-aprendizagem instituída, ampliando conceitos e espaços de formação com ênfase no aprendizado coletivo no trabalho e sobre ele, o que causa impacto no cuidado de enfermagem.

Palavras-chave educação em enfermagem; educação permanente; educação em saúde; prática profissional; aprendizagem.

\begin{abstract}
The article discusses the training process educator nurses get in the hospital context from the perspective of permanent education in health, highlighting the experiences that constituted this process, the meanings of the training, and the changes that took place in the development of nursing care based on meaningful learning. This was an exploratory, descriptive qualitative study developed through focus groups with seven nurses working in the Continuing Education Program in Nursing at a university hospital in Porto Alegre, Rio Grande do Sul, Brazil, in 2010, the light of the assumptions set forth under the National Policy of Permanent Education in Health. The thematic analysis of the content made using the NVivo 8.0 software for organizing and categorizing data. The results showed that the nurses' participation in the program resulted in opening to several changes in their work process and in the established teaching-learning modeling, expanding training concepts and spaces with an emphasis on collective learning at work and on it, which impacts nursing care.
\end{abstract}

Keywords nursing education; continuing education; health education; professional practice; learning. 


\section{Introdução}

A formação em enfermagem no Brasil foi influenciada fortemente pelo modelo americano, mais precisamente a partir da instalação da Fundação Rockefeller, em 1921, a qual teve papel decisivo na implantação da enfermagem moderna no país, inclusive no modelo pedagógico que sustentaria as ações educativas nas escolas fundadas posteriormente (Kruse, 2004; Lopes, 2007). Em 1922, ocorreu a criação da primeira escola de enfermagem no país, 4 a Escola de Enfermeiras do Departamento Nacional de Saúde Pública, denominada posteriormente, em 1923, como Escola de Enfermagem Anna Nery (Lopes, 2007). As escolas mencionadas desenvolviam sua prática formativa valorizando o saber médico, o aspecto curativo e o cenário do hospital no desenvolvimento das atividades de aprendizado, com ênfase na disciplina das enfermeiras/cuidadoras (Kruse, 2004). Tais escolas assumiram o modelo 'flexneriano' como orientador para o ensino e a assistência na enfermagem, incorporando o tecnicismo e a fragmentação do cuidado como forma de organização do trabalho profissional (Lopes, 2007). Entre 1940 e 1950, houve uma forte mobilização nacional que desenhava novos contornos para a profissão, representados pelo perfil das enfermeiras brasileiras, que não atendia exatamente ao modelo americano até então preconizado, culminando com a criação da Associação Brasileira de Enfermagem (ABEn) (Lopes, 2007).

Nas décadas seguintes, de 1950 e 1960, as instituições de ensino de enfermagem e a ABEn vivenciaram um período de grandes discussões acerca dos currículos e da legislação em enfermagem, que levaram à proposição de um currículo mínimo para os cursos de enfermagem nos anos 1970 (Lopes, 2007). Nessa década, o modelo de saúde vigente permanecia voltado para a tecnologia, era basicamente hospitalocêntrico e biomédico, seguindo também uma tendência de atender às necessidades de apenas uma parcela da população, a qual dispunha de maior poder aquisitivo e tinha acesso aos serviços de saúde (Lopes, 2007).

Nos anos 1990, abriu-se uma nova perspectiva para a enfermagem, pois a partir da $8^{\text {a }}$ Conferência Nacional de Saúde e do $1^{\circ}$ Seminário Nacional de Diretrizes para a Educação em Enfermagem (Senaden), em 1994, de forma ainda tímida, mas emergente, intensificaram-se as reflexões sobre os processos de formação e cuidado. A saúde pública ganhou destaque nesse processo, em que o foco de atenção da enfermagem passou a ocupar-se da produção de cuidados para o coletivo, com ênfase na inclusão e na promoção da saúde. Essas iniciativas se expandiram e mais tarde culminaram na presença da assistência de enfermagem nos vários cenários de cuidado, principalmente no Programa de Saúde da Família, tomado como estratégia de investimento na atenção primária em saúde no contexto do Sistema Único de Saúde (SUS) (Geovanini et al., 2010). Essa nova postura da enfermagem - 
com ênfase na atenção primária em saúde, em detrimento do foco hospitalar - ampliou os espaços de atuação e autonomia dos profissionais da enfermagem, além de ter propiciado a retomada da atenção integral ao humano, um fazer historicamente pertencente ao ato de cuidar.

As ações de enfermagem, revistas nas últimas três décadas, envolveram também a (re)configuração da formação em enfermagem, em virtude de mudanças nas políticas públicas de saúde e nos modelos assistenciais instituídos (Faustino e Egry, 2002). Tais mudanças foram consubstanciadas por um modelo de saúde defasado e insuficiente do ponto de vista da atenção à saúde como direito universal e pleno exercício de cidadania. Assim, no atual cenário de formação, o modelo hegemônico que sustentou - e ainda sustenta, em algumas instituições - a concepção de saúde restrita à dimensão biológica e individual mostrou-se insuficiente para atender às demandas que emergiram a partir das proposições do SUS (Silva et al., 2009).

No contexto do SUS, a formação é compreendida como um processo contínuo, sendo o espaço do trabalho valorizado como lócus privilegiado de aprendizado e, consequentemente, de formação (Lopes, 2007; Brasil, 2004a). A constituição e a implementação do SUS, com ênfase nas interfaces e singularidades entre trabalho, educação e saúde, têm exigido novas estratégias formativas para alinhamento a essas propostas, diante da necessidade de readequação da formação profissional para atuação nas instituições de saúde (Amâncio Filho, 2004).

A partir do reconhecimento de que a formação em saúde não tem acompanhado o dinamismo das propostas do SUS, e de que ambos vêm operando em lógicas distintas (Amâncio Filho, 2004; Ceccim e Ferla, 2009, o Ministério da Saúde (MS), em 2003, instituiu a Secretaria de Gestão do Trabalho e da Educação na Saúde, com o objetivo de formular políticas públicas no âmbito do trabalho e da educação das profissões da saúde, orientando assim a formação dos trabalhadores da área. Para tanto, em 2004 foi implantada a Política Nacional de Educação Permanente em Saúde (PNEPS), uma proposta do Departamento de Gestão da Educação na Saúde para promover a formação dos trabalhadores do SUS (Stroschein e Machado, 2009).

A PNPES foi proposta pelo MS como estratégia do SUS para a formação e o desenvolvimento dos trabalhadores da saúde, com o intuito de provocar nestes a autoanálise e a autogestão do processo de trabalho, o que vinha ao encontro das proposições do sistema. A referida política explicita a relação da proposta de formação com os princípios e as diretrizes do SUS, da atenção integral à saúde e a construção da Cadeia do Cuidado Progressivo à Saúde na rede do SUS (Brasil, 2004a). A educação permanente é uma proposta centrada no enfrentamento dos problemas que emergem do trabalho cotidiano nos serviços de saúde (Silva, Conte e Vial, 2009). Nesse sentido, o desafio apresentado pela proposta foi o de estimular o desenvolvimento dos 
profissionais sobre um contexto de responsabilidades e necessidades de atualização, considerando o serviço, o trabalho, o cuidado, a educação e a qualidade da assistência - elementos importantes e indissociáveis em sua prática (Sena e Ricaldoni, 2006). A educação também é indicada como uma das estratégias para se alcançar o desenvolvimento da relação entre o trabalho e a educação, em que a atividade do trabalhador pode ser o ponto de partida de seu saber, determinando sua aprendizagem subsequente (Lopes, 2007). Pode-se dizer, então, que a educação permanente em saúde (EPS) não é algo que se acrescenta a um sistema dado, não é um novo setor, um novo campo, e sim uma nova perspectiva, que leva os educadores a redefinir toda e qualquer educação (Furter, 1985). Essa nova perspectiva serve para interrogar as práticas, ativar a composição de planos de consistência das equipes de saúde e organizar o ensino orientado pelo desenvolvimento das capacidades sensíveis e de problematização (Ceccim, 2004).

No Hospital de Clínicas de Porto Alegre (HCPA), cenário da pesquisa que originou os dados apresentados neste artigo, a iniciativa de adotar a EPS como dispositivo educativo foi articulada por um intenso movimento entre as diversas áreas do hospital, principalmente dentro da enfermagem. Para o desenvolvimento dessa nova proposta educativa na perspectiva da EPS, houve o apoio político-administrativo das chefias de enfermagem, da Coordenação do Grupo de Enfermagem e da Coordenadoria de Gestão de Pessoas, configurando um clima organizacional favorável à sua implantação. A proposta objetivou melhorar o processo de trabalho e qualificar a assistência de enfermagem prestada ao usuário, estando o Serviço de Educação em Enfermagem (Sede) à frente de todo o processo de desenvolvimento das ações educativas, aí incluída a preparação das(os) enfermeiras(os) para atuação como facilitadoras(es) de ações de educação permanente na instituição. Anteriormente, as atividades educativas dirigidas aos trabalhadores do hospital eram desenvolvidas na perspectiva da educação continuada (EC), representando uma continuidade do modelo escolar ou acadêmico, centralizado na atualização de conhecimentos, geralmente com enfoque disciplinar, embasado em técnicas de transmissão, realizado por meio de treinamentos e cursos desenvolvidos de forma pontual. A definição de temas era feita por áreas específicas, visando à atualização profissional e, em geral, com uma abordagem bancária/tradicional de educação (Brasil, 2009). A partir da adoção do referencial da EPS para o desenvolvimento das ações educativas dirigidas à enfermagem, houve uma mudança substancial na lógica da formação em serviço para capacitação dos profissionais dessa área. As ações passaram a ser planejadas de modo mais participativo, ampliando-se os espaços de diálogo e dando-se maior ênfase às necessidades referidas pelos trabalhadores. Além do desenvolvimento de ações de forma articulada com o trabalho, 
começou-se a utilizar a metodologia da problematização como orientadora das capacitações em serviço para as equipes de enfermagem da instituição.

A necessidade de adesão a um novo projeto de formação em serviço, com base no referencial da EPS, demandou das enfermeiras que atuam no programa o desenvolvimento de habilidades para um trabalho mais dinâmico e participativo com as suas equipes de trabalho, com ênfase na abertura para a escuta, o compartilhamento dos saberes, a divisão do poder instituído e a possibilidade de coautorias no processo formativo - elementos constituintes da PNEPS. Atualmente, essas enfermeiras assistenciais são consideradas pela instituição como facilitadoras dos processos de formação em serviço. Nessa transição entre uma modelagem e outra de formação em serviço, as enfermeiras têm demonstrado certo despreparo para atuar numa perspectiva diferente do modo tradicional de educar no e para o trabalho em saúde. Relativizar o valor do conhecimento técnico para a realização da 'boa prática', definir necessidades e planejar de forma participativa as ações educativas a serem implementadas, substituir o investimento na apropriação unilateral de saberes por metodologias inclusivas, atuar como facilitadora dos processos de aprendizagem e reconhecer o caráter dialógico da educação são alguns dos desafios enfrentados nesse contexto.

Embora a EPS tenha se difundido gradativamente nos espaços de trabalho da enfermagem desde 2005, quando foi implantada na instituição, somente em 2008 o conjunto de ações educativas dirigidas à formação continuada dos profissionais da enfermagem passou a se chamar Programa de Educação Permanente (Pepe), legitimando, de uma vez por todas, a proposta da EPS como referencial orientador dessa formação. O programa é composto por sete enfermeiras e uma pedagoga, que atuam especificamente no Sede, e por 12 enfermeiras assistenciais dos diversos serviços de enfermagem da instituição, denominadas AD/Pepe. ${ }^{5}$ Essas enfermeiras assistenciais são designadas por suas chefias para atuarem no Pepe, cumprindo uma carga horária de três a seis horas semanais, destinadas ao planejamento, à organização, ao acompanhamento e à realização de ações de educação com as equipes de enfermagem. Até então, as enfermeiras assistenciais, representantes dos serviços de enfermagem, vinham desenvolvendo suas atividades em uma perspectiva mais tradicional de educação continuada.

Ao se considerar a necessidade de dar continuidade às ações educativas com as equipes de enfermagem e, ao mesmo tempo, iniciar um processo de transição da educação continuada para a educação permanente, mesmo antes de se ter um grupo de enfermeiras preparadas para o trabalho educativo embasado na nova perspectiva, abriram-se espaços formativos para as enfermeiras assistenciais que compunham o grupo $\mathrm{AD} / \mathrm{Pepe}$ - os quais extrapolaram os limites formais de preparação para o trabalho educativo. Nesse 
contexto, a própria experiência de implementar a EPS acabou tornando-se uma oportunidade de se constituir como um espaço de formação. Tal espaço foi se constituindo mediante uma práxis viabilizada em encontros do grupo do Pepe para a problematização das experiências educativas vividas no passado, orientadas pelo modelo tradicional da educação continuada; e no presente, redirecionadas segundo a perspectiva da EPS (e os saberes apreendidos, indagados ou atualizados em tais experiências). Nesse processo de articulação entre as experiências prévias e as atuais, buscava-se o sentido do que se estava vivenciando como meio de facilitar as ações de EPS, de modo a utilizar esses novos sentidos como elementos da aprendizagem significativa de saberes para a prática do cuidado em enfermagem, assim como para a formação em serviço.

São apresentados aqui dados oriundos da dissertação Educação permanente e aprendizagem significativa no contexto hospitalar: a perspectiva de enfermeiras educadoras (Flores, 2011), que resultou de uma pesquisa realizada com o objetivo de conhecer as experiências de aprendizagem significativa de enfermeiras facilitadoras de ações de educação permanente no contexto hospitalar e analisar as implicações dessa aprendizagem na transformação das suas práticas de cuidado em saúde.

\section{Aprendizagens significativas: o caminho metodológico}

O artigo aborda o processo de formação vivenciado por enfermeiras educadoras no contexto hospitalar, na perspectiva da educação permanente em saúde, com destaque para as experiências que constituíram esse processo, os sentidos dessa formação e as mudanças decorridas no desenvolvimento do cuidado de enfermagem a partir das aprendizagens significativas.

O estudo foi do tipo qualitativo, exploratório-descritivo, sendo desenvolvido em um hospital universitário. Foram sujeitos de pesquisa sete enfermeiras educadoras que atuam no Pepe, as quais, além de estarem atuando no programa há no mínimo seis meses, aceitaram o convite para participar do estudo. Ficou definido que, assim que houvesse de seis a oito participantes inscritas, a formação do grupo de sujeitos do estudo estaria concluída, considerando o que ressalta a literatura, indicando que grupos menores de sujeitos propiciam maior participação nas discussões e interação entre os participantes (Trad, 2009; Dias, 2000).

A coleta de informações deu-se por meio de grupos focais (GFs). Foram realizados três GFs com duração de duas horas cada, no mês de agosto de 2010, desenvolvidos segundo uma agenda prévia contendo questões orientadoras, em salas de aula previamente agendadas no hospital em questão, no horário inverso ao turno de trabalho dos sujeitos. Houve a participação de 
uma enfermeira observadora, que auxiliou na organização e nos registros das falas dos sujeitos. A técnica de GF é apropriada para estudos que buscam entender atitudes, preferências, necessidades e sentimentos. Grupos focais também apresentam excelente potencial exploratório, podendo servir para investigar questões complexas no desenvolvimento e na implementação de programas. Contudo, o valor principal dessa técnica fundamenta-se na capacidade humana de formar opiniões e atitudes na interação com outros indivíduos (Krueger, 1988).

As informações coletadas foram analisadas por meio de procedimentos de análise de conteúdo, do tipo temático, conforme Minayo (2006). Para a identificação das falas na análise, foi adotada a sigla 'Enf' para designar as enfermeiras participantes da pesquisa, numerando-as seguindo a ordem alfabética. Para a organização e a categorização dos dados, utilizou-se como recurso complementar o software NVivo versão 8.0, programa que organiza o material para a análise em pesquisas qualitativas e possui ferramentas de codificação e armazenamento de textos em categoria específica (Teixeira, 2010).

A análise e a interpretação das informações obtidas nos encontros de GF resultaram em três categorias: ‘O (des)preparo da enfermeira para o diálogo entre a formação e a prática do cuidado'; 'Os saberes investidos: o desafio de romper com o instituído e o privilégio de se tornar educadora na perspectiva da EPS'; e a 'A ressignificação do cuidado de enfermagem a partir do aprendizado com sentido: potência e/ou fragilidade?' Neste artigo, destacou-se a análise do conteúdo da primeira categoria citada.

As considerações bioéticas foram seguidas de acordo com a resolução n. 196/96 do Conselho Nacional de Saúde, no que se refere aos aspectos éticos que envolvem pesquisas em seres humanos. O projeto foi aprovado pelo Grupo de Pesquisa e Pós-Graduação (GPPG) do HCPA, com o número 100229, e pela Comissão de Pesquisa da Escola de Enfermagem da Universidade Federal do Rio Grande do Sul (UFRGS). O termo de consentimento livre e esclarecido (TCLE), seguindo as orientações do comitê GPPG/HCPA, foi redigido no formato de convite para os sujeitos. O TCLE foi impresso em duas vias, sendo que uma delas permaneceu com a pesquisadora e a outra entregue às participantes da pesquisa.

\section{Analisando e discutindo a formação sob a ótica de enfermeiras educadoras}

Na categoria intitulada 'O (des)preparo da enfermeira para o diálogo entre a formação e a prática do cuidado', a formação inicial desenvolvida durante o período da graduação ganhou destaque, tendo em vista que os saberes aprendidos nesse período influenciam na construção do conhecimento e na renovação das aprendizagens. Sabe-se que os saberes e os conhecimentos já 
dominados dão suporte na construção de novos conhecimentos e a favorecem, na realidade construída anteriormente pelo trabalhador (Roschke, 1997). O trecho a seguir ilustra as vivências dessas enfermeiras na graduação e como elas percebem sua relação com a ação educativa.

O enfermeiro tem muito essa questão da insegurança... [referindo-se à ação educativa] (Enf. 2).

Pois é, mas o que isso retrata: a nossa formação. Porque como a gente se dividia na faculdade, aquelas que gostam da assistência, aquelas que gostam de dar aula, aquelas que gostam de pesquisa... Vai ser aquela [enfermeira] que não vai desenvolver o papel de educador junto com a assistência (Enf. 1).

É como se o enfermeiro educador não entendesse nada de assistência e o assistencial não tivesse que se preocupar com educação (Enf. 5).

O depoimento das enfermeiras sobre esse período da formação inicial sugere a existência de lacunas, na medida em que essa experiência não as preparou para estabelecer a relação entre cuidar e educar. Tal perspectiva contraria a premissa de que a universidade deveria assumir papel fundamental na aproximação da formação profissional com o conjunto de necessidades sociais e políticas da população (Ito et al., 2006). Nesse cenário, percebe-se o descompasso com aquilo que é preconizado nas atuais diretrizes curriculares na área da enfermagem, que destaca a importância da formação em preparar para a complexidade do trabalho em saúde, numa abordagem crítica e contextualizada e na qual se invista na aproximação entre as interfaces que envolvem as práticas de cuidar e educar (Brasil, 2001). As falas a seguir reforçam a percepção das enfermeiras acerca da fragmentação do cuidado pela formação e o seu despreparo para a ação educativa no contexto do trabalho em saúde.

Isso [a divisão entre cuidar e educar] me frustra um pouco. Acredito que é uma coisa que tem que ser de todo enfermeiro, ir atrás, buscar, ele mesmo buscar e fazer a sua equipe buscar conhecimento, capacitação, melhorias, e isso eu vejo que de certa forma se espera que isso aconteça que alguém traga pronto. A gente vê que eles [os enfermeiros] querem que tu faças (Enf. 6).

Pois é, na nossa formação as pessoas se dividem, aquele que gosta de apresentar trabalhos em grupo... “Ah, não, então ele quer ser professor, deixa, eu não gosto, então deixa." E essa pessoa que se retrai naquele momento vai ser aquela que na assistência não vai desenvolver o papel de educador junto com a assistência. 
Então, claro que depois [no trabalho do Pepe] o nosso papel é tentar motivar, aproximar esse abismo entre enfermeiro assistencial e enfermeiro educador (Enf. 1).

Depreende-se do diálogo das enfermeiras educadoras que a formação inicial transmitiu para elas uma concepção de processo de cuidado como algo fragmentado, desarticulado. Práticas que, uma vez instituídas, acabaram por distanciá-las do trabalho em saúde - bem como das propostas do MS por meio das diretrizes da PNEPS, de mudanças no processo de atenção em saúde em todos os cenários de cuidado, alicerçada na educação permanente por meio da contextualização e da aprendizagem-trabalho (Brasil, 2004b). Nessa perspectiva, faz-se necessário investir na integração entre educação e saúde para a transformação das práticas, mediante uma ação coletiva que supere e crie oportunidades para a melhoria da atenção e para a qualificação do ensino no campo da saúde (Silva et al., 2009).

Analisando os depoimentos do grupo de enfermeiras educadoras, percebe-se que, mesmo havendo forte influência de uma modelagem mais tradicional de educação na sua formação, de algum modo foi possível questionar a tendência à divisão de saberes educativos e assistenciais, na medida em que reforçaram em seus depoimentos a inseparabilidade entre esses saberes. Esse avanço na interface entre os saberes é enfatizado na fala da Enf. 6: "Enfermeiro por si só é educador, seja ele da ação Pepe ou não."

Tal afirmação confirma que as atitudes e as ações realizadas no cotidiano laboral têm íntima relação com as experiências anteriores e os saberes prévios, adquiridos na formação. Como já destacado por outros autores, existe uma forte ligação entre o que se vivencia na graduação com referência à educação em saúde e a forma como esta é reproduzida no contexto da prática profissional (Amâncio Filho, 2004; Ito et al., 2006; Colomé, 2007). A reprodução de modos de ser do profissional enfermeiro no que se refere ao componente educativo revela os atravessamentos sociais e culturais que constituem os sujeitos, com base em suas experiências anteriores. Nesse sentido, as oportunidades vivenciadas pelos sujeitos e as suas concepções de vida vão incidir na replicação de fazeres no seu campo de atuação. A EPS, como política de formação na qual se associam trabalho e cidadania, interroga esses fazeres construídos socialmente e estimula a aprendizagem de si, dos entornos e dos papéis profissionais, estimulando novos contornos à formação em saúde (Ceccim e Ferla, 2009).

Nos serviços de enfermagem, a utilização dessa modalidade de educação tradicional, desenvolvida no estilo 'treinamento', ainda é amplamente utilizada na realização das atividades de educação continuada (Brum, 2009). Como reconhecem outros autores, no campo dos serviços de saúde, mesmo tendo havido modificações importantes acompanhadas de uma reflexão 
crítica sobre as tendências clássicas, ainda se mantém fortemente o predomínio dessa lógica na maioria das instituições (Colomé, 2007; Brum, 2009; Davini, 2009). O relato sobre o modo como as enfermeiras organizavam e desenvolviam suas atividades de educação em serviço anteriormente ao ingresso no Pepe ilustra esse argumento:

Quando eu trabalhava com educação continuada, treinamento nas outras instituições era uma coisa muito de aulinha, não trabalhava na pedagogia da problematização (Enf. 1).

É, antes [nas experiências anteriores ao Pepe] eu também ia e expunha... Por exemplo, eu tinha que dar aula sobre apendicite, eu ia e expunha a aula sobre apendicite, o que que é, onde está o apêndice... (Enf. 7).

No início [quando entrei no Pepe], eu também não sabia bem como é que funcionava. Gerou um pouco de angústia, lembro que vim em uma reunião e elas falando de rodadas de conversa, de grupo focado, de problematização, e eu só olhando, não entendendo quase nada (Enf. 5).

Eu também, no começo, quando eu vim para cá [para o Pepe], a parte de educação eu fazia bem formal [concordando com Enf. 3] (Enf. 4).

Os depoimentos sugerem que a atuação no Pepe e o contato com a EPS representaram para essas enfermeiras a aproximação com um referencial inédito no conjunto de saberes sobre educação e enfermagem já vivenciados. A maioria das enfermeiras relatou que, nas experiências anteriores de formação continuada, reproduziam o ensino verticalizado e descontextualizado, 'estilo graduação' - embora, algumas vezes, até ousassem utilizar outras maneiras de ensinar que pudessem facilitar a aprendizagem pretendida, mas sem muita convicção ou justificativa teórica para o uso das alternativas.

O que me chamou a atenção, quando eu vim aqui para a escola [Escola Técnica de Enfermagem], é que todo mundo falava em teoria da dramatização, problematização... Mas na realidade já era o que eu vinha fazendo o tempo inteiro, só que hoje em dia se fala em problematização, participação, e isso tudo eram coisas que se fazia instintivamente (...) já era meu estilo teatreiro de ensinar (Enf. 6).

Apesar de ser usual a utilização de modelagens mais tradicionais de educação no contexto da enfermagem, os dados sugerem a existência de brechas para romper com o paradigma tradicional, desenvolvendo ações educativas mais interativas. A fala da Enf. 6, em destaque, indica que essa enfermeira já trabalhava numa perspectiva bem próxima da EPS, mesmo antes do seu 
ingresso no programa. Esse indicativo reforça o argumento de que nem tudo foi aprendido no Pepe, ou seja, que o processo de aprendizagem é contínuo.

No hospital, a nova proposta de formação, com base na EPS, passou a exigir das enfermeiras educadoras a apropriação teórica e de conceitos relativos à educação, saúde e trabalho que fossem alinhados à PNEPS. Assim, promover a aproximação dessas enfermeiras com o referencial que deveria sustentar sua ação educativa no Pepe tornou-se fundamental, na medida em que a proposta era mudar a lógica das ações de educação em serviço das equipes de enfermagem, exigindo uma compreensão do trabalho educativo bastante distinta daquela com a qual elas estavam familiarizadas. O início dessa transição entre os saberes já aprendidos e os novos saberes, viabilizado de forma mais intensiva a partir do ingresso no Pepe, e o contato com novas formas de ensinar e aprender podem ser visualizados nos depoimentos a seguir:

Quando vim para fazer as atividades da $\mathrm{AD}$, fui buscar algumas coisas por mim, porque eu não tinha isso... Esse movimento [de busca] foi que me ajudou bastante a descobrir isso [referindo-se às novidades no Pepe], mas, ao meu ver, aprendi isso fazendo no dia a dia, trabalhando... (Enf. 2).

Eu, claro, tinha conhecimentos prévios, mas aqui no hospital a gente trabalha de uma maneira bem diferente. Eu vinha de dois hospitais onde eu trabalhava só em UTI, então a visão da enfermeira de UTI é aquele espaço ali, a gente não imagina o que aconteça fora (Enf. 5).

[Estar no Pepe] são novidades absolutas (...) no outro hospital que eu trabalhava, isso não existia [preocupação com a questão educativa]. Pelo contrário, o que nos cobravam é uma boa enfermeira, aquela que está em consonância com custos, com planejamento estratégico, lucro, aquela visão bem capitalista, tantas cirurgias, tanto de rendimento... (Enf. 3).

É, acho que há muita novidade positiva da construção da enfermagem [referindo-se ao Pepe] (Enf. 1).

A vivência de 'novidades' no contexto da educação oportunizado pelo trabalho no Pepe parece ter estimulado o grupo de enfermeiras a buscar estratégias para promover a aproximação entre os 'modos anteriores de fazer' e os fazeres renovados. Como destacado na literatura, é o desejo que coloca o homem em movimento (Roschke, 1997; Aranha, 1996; Kastrup, 2002). Nessa perspectiva, parece que o desejo de mudar, que resultou dessas primeiras experiências e aprendizagens no Pepe, não se reduziu à vontade de transformar o modo pessoal de trabalhar, estendendo-se também ao trabalho coletivo. 
Esse movimento na direção do outro parece ter relação com o reconhecimento de que mudanças no processo de cuidar - aí incluídas as transformações no modo de educar - só são efetivas se forem aceitas e assumidas pelo coletivo. Os dados indicam que, ao se depararem com a novidade, com o desconhecido, as enfermeiras assumiram uma atitude de busca, movendo-se em direção às soluções para suas inquietações, a partir do desejo de mudança. Essa possibilidade de revisão dos saberes anteriormente aprendidos, viabilizada pela aproximação com o referencial da EPS e estimulada pela oportunidade de reflexão e problematização sobre as questões relativas à formação no/para o trabalho, representou para as enfermeiras a possibilidade de uma revisão mais ampla dos 'modos de cuidar' que vinham pautando suas práticas profissionais. A análise sugere que tal movimento foi estimulado, em parte, pelo desconforto gerado pelo 'dar-se conta' de que os saberes que possuíam eram insuficientes para dialogar com as necessidades da formação em saúde. A detecção e o contato com os desconfortos experimentados no cotidiano do trabalho são elementos indispensáveis para a mudança de uma pessoa ou de uma organização. Não se constata o desconforto mediante aproximações discursivas externas. $\mathrm{O}$ desconforto tem que ser intensamente admitido, vivido e percebido, para que de fato produza transformações (Ceccim, 2005). O diálogo a seguir é indicativo da existência de transformações importantes nos 'modos de fazer' do cotidiano de trabalho das enfermeiras, promovidas pela interseção do questionamento do 'antes' com a experiência de aprender novidades na prática de 'hoje':

Então [é importante] todo esse processo de desconstrução de alguns vícios e a construção de algo realmente fundamentado [referindo-se aos aprendizados no] (Enf. 1).

Bom, na verdade foram vários [aprendizados no Pepe]. Primeiro, saber a diferença da educação permanente, educação continuada, como é que se faz a rodada. Eu acho que as rodadas que a gente faz são de crescimento, bem importantes, essa troca de conhecimentos que a gente tem... Isso faz com que a gente aprenda também a trabalhar (...) então essas coisas, assim, que estão me acrescentando bastante (Enf. 5).

Assim como a colega [Enf. 5], eu também só tenho crescido com ela [a experiência nova no Pepe], em termos de montar a capacitação, de ser orientadora, de fazer (...) capacitação... O que foi mais difícil foi a metodologia, e nisso eu tenho crescido muito (Enf. 4).

Ao considerar a EPS como orientadora dos processos de formação em saúde, torna-se essencial a valorização de outros aspectos do trabalho além dos normativo-administrativos, tomados como intrínsecos ao trabalho do 
enfermeiro. Faz-se necessária, também, a implicação do trabalhador com a autoria responsável das ações cotidianas no trabalho desenvolvido (Ceccim, 2005). No contexto estudado, as aprendizagens com sentido foram viabilizadas com base em oportunidades oferecidas pelo trabalho e pelas conexões estabelecidas com os pares e com a equipe multiprofissional. Tal argumento se apoia na literatura, a qual afirma que a aproximação do mundo do trabalho ao da educação pode ser considerada como lócus privilegiado de aprendizagens significativas, pois estas se constituem mediante as situações cotidianas dos trabalhadores, as quais estimulam a problematização e a reflexão sobre o seu fazer, determinando consequentemente o significado da ação (Carvalho e Ceccim, 2006). A forma como as enfermeiras definem os elementos constituintes do processo de aprendizagem vivenciado por elas no Pepe é explicitada no trecho que segue:

A palavra que define esse processo [no Pepe] é ser aprendiz. Todas as dimensões que a gente se insere, esse sentimento [de ser aprendiz] aflora, de todo o aprendizado de ser educador e ser educando ao mesmo tempo (Enf. 1).

Eu fui aprendendo no dia a dia, aqui, com as gurias da escola [ETE], e foi em um momento que me ajudou bastante, porque eu estava começando a entrar no grupo de humanização, que discute muito essas questões do SUS, dos problemas do sistema, e vinculado a isso as questões da educação permanente (Enf. 2).

Foi uma transformação muito grande para mim [a participação no Pepe] (...) um crescimento, foi bem significativo, eu estou sempre aprendendo com as gurias da escola [ETE] também (Enf. 5).

Acho que a principal atualização que aconteceu comigo [referindo-se ao Pepe] é que eu não sou quem está coordenando aquela capacitação, não sou a pessoa que detém todo o saber (Enf. 3).

Os depoimentos revelam que, para essas enfermeiras, o aprendizado com uma nova roupagem foi consituindo-se ao longo da trajetória no Pepe, ou seja, a própria experiência de se tornar educadora Pepe foi oportunidade de aprendizagem de novos saberes para as enfermeiras educadoras, indagando, rejeitando, superando ou complementando aprendizagens anteriores. O processo de formação que tem resultado daí parece incluir a compreeensão de que a formação deve ser permanente e que a construção do conhecimento se faz no encontro, na interdisciplinaridade e na contextualização do aprendido e do vivido. Essa perspectiva integradora indica a EPS como ferramenta para a dinamização dos processos organizacionais, no que diz respeito à transformação das práticas, da lógica pedagógica e da capacidade de gestão 
dos trabalhadores sobre seu processo de trabalho (Davini, 2009). Desse modo, a EPS não pode ser tomada somente como uma prática de ensino-aprendizagem, mas sim como uma política de ligação entre ensino, trabalho e cidadania (Brasil, 2004a; Ceccim e Ferla, 2009).

\section{Considerações finais}

Pode-se pontuar que a graduação não preparou suficientemente as enfermeiras facilitadoras para assumirem o diálogo necessário entre cuidar e educar, considerando que ambas as atividades se complementam. Também há um distanciamento dessas profissionais em relação às proposições e atuais políticas de formação em saúde. Evidenciam-se a prevalência da modelagem de educação bancária-tradicional das instituições formadoras e a utilização de metodologias pouco estimuladoras à participação nos contexos educativos.

No entanto, a análise revelou que mesmo que as enfermeiras tenham sido formadas numa perspectiva tradicional de educação, torna-se possível para elas forjar outras formas de educar no seu espaço de trabalho, bem como produzir movimentos de mudança em níveis individual, coletivo e institucional. A experiência no programa de educação viabilizou a essas enfermeiras abertura institucional para novos 'modos de saber' e novos 'modos de fazer', rompendo padrões até então estabelecidos como 'possíveis' no espaço de trabalho, ou seja, imprimindo um nova modelagem mais afeta às necessidades do atual contexto de educação e saúde. Essa nova modelagem permitiu um alargamento dos processos de formação das equipes de enfermagem, repercutindo na qualidade e na segurança da assistência ao paciente.

Concluiu-se que a existência de um programa de educação permanente no contexto hospitalar propicia a construção de coletivos fortalecidos, pois fomenta aprendizagens significativas e amplia a possibilidade de implementação das mudanças almejadas nas ações de educação em serviço - mesmo que, nesse espaço, ainda convivam modelos tradicionais e modelagens ampliadas de formação em enfermagem e saúde. Nesse sentido, cabe destacar que, apesar dos avanços institucionais, há limitações; inclusive a própria nomenclatura 'ação diferenciada', utilizada como denominação para as atividades educativas, é contraditória, tendo em vista que todos os investimentos reforçam a necessidade de integralidade de ações. Portanto, esse ainda é um ponto passível de discussão institucional.

Considerando que as aprendizagens significativas desse grupo de enfermeiras educadoras foram motivo de mudança, a aposta é que como facilitadoras elas sigam investindo nessa lógica e ativem processos que despertem também o protagonismo dos seus pares em direção à renovação e à recriação do trabalho. 
Este estudo não se propôs a finalizar qualquer discussão acerca da formação em enfermagem e da promoção de aprendizagens significativas nesse cenário, em razão da complexidade do tema. Faz-se necessário que sigamos investindo em estudos que possam continuar desvelando possibilidades da formação na perspectiva de uma lógica ampliada. Assim, algumas questões ainda merecem atenção: como fomentar a formação em saúde em geral - e a da enfermagem, em particular - numa perspectiva dialógica e participativa no contexto hospitalar, considerando esse cenário marcado por processos burocratizados, saberes fragmentados e permeado por relações de poder?

\section{Colaboradores}

Giovana Ely Flores é a autora principal; Dora Lucia Leidens de Oliveira, orientadora; e Denise Antunes de Azambuja Zocche, revisora.

Resumen El artículo aborda el proceso de formación experimentado por enfermeras educadoras en el contexto hospitalario, en la perspectiva de la educación permanente en salud, resaltando las experiencias que constituyeron ese proceso, el sentido de esa formación y los cambios ocurridos en el desarrollo del cuidado de enfermería con base en aprendizajes significativos. Se trata de un estudio cualitativo investigativo-descriptivo, desarrollado por grupos focales con siete enfermeras que actuaban en el Programa de Educación Permanente en Enfermería, en un hospital universitario de Porto Alegre, Rio Grande do Sul, Brasil, en 2010, a la luz de los preceptos de la Política Nacional de Educación Permanente en Salud. El análisis del contenido, de tipo temático, fue realizado utilizándose el software NVivo 8.0 para organización y categorización de los datos obtenidos. Los resultados mostraron que la participación de las enfermeras en el programa resultó en una apertura para diversos cambios en su proceso de trabajo y en el modelado de la enseñanza-aprendizaje instituida, ampliando conceptos y espacios de formación con énfasis en el aprendizaje colectivo en el trabajo y sobre él, hecho que ha ocasionado impactos en el cuidado de enfermería. Palabras clave educación en enfermería; educación permanente; educación en salud; práctica profesional; aprendizaje. 


\section{Notas}

1 Hospital de Clínicas de Porto Alegre, Porto Alegre, Rio Grande do Sul, Brasil. <gflores@hcpa.ufrgs.br> Correspondência: Avenida Cristóvão Colombo, 4.105/1.703, Torre B, CEP 90560-005, Porto Alegre, Rio Grande do Sul, Brasil.

2 Universidade Federal do Rio Grande do Sul, Escola de Enfermagem, Porto Alegre, Rio Grande do Sul, Brasil.

$<$ dora@hcpa.ufrgs.br>

3 Universidade do Estado de Santa Catarina, Chapecó, Santa Catarina, Brasil.

$<$ denise9704@gmail.com>

4 Há registros na literatura que sinalizam a existência de escolas que também desenvolviam formação em enfermagem entre 1890 e 1917, com ênfase na formação técnica. Ver em <www.webartigos.com/artigos/historia-da-enfermagem/52207>, endereço eletrônico acessado em 17 de janeiro de 2016.

${ }^{5}$ As ações diferenciadas (ADs) foram instituídas no HCPA a partir da proposição do sexto turno de trabalho para enfermeiras(os). A partir desse novo arranjo de carga-horária das(os) enfermeiras(os), durante os dias da semana houve a formalização de grupos de trabalho, com representantes dos diversos serviços de enfermagem. Tais programas foram implementados na instituição tendo como objetivo a melhoria da assistência prestada aos usuários.

\section{Referências}

AMÂNCIO FILHO, Antenor. Dilemas e desafios da formação profissional em saúde. Interface: Comunicação, Saúde, Educação, Botucatu, SP, v. 8, n. 15, p. 375-380, 2004.

ARANHA, Maria L. A.; MARTINS, Maria H. P. Nada se faz sem paixão. Homem: ser de desejo. In: ARANHA, Maria L. A.; MARTINS, Maria H. P. Temas de filosofia. São Paulo: Moderna, 1996. 144-148.

BRASIL. Conselho Nacional de Educação. Resolução CNE/CES n. 3, de 7 de novembro de 2001. Institui diretrizes curriculares nacionais do curso de graduação em enfermagem. Brasília: Câmara de Educação Superior, 2001.

BRASIL. Ministério da Saúde. Secretaria de Gestão do Trabalho e da Educação na
Saúde. Política de educação permanente e desenvolvimento para o SUS: caminhos para educação permanente em saúde - polos de educação permanente em saúde. Brasília: Ministério da Saúde, 2004a.

BRASIL. Portaria n. 198/GM/MS, 13 de fevereiro de 2004. Institui a Política Nacional de Educação Permanente em Saúde como estratégia do Sistema Único de Saúde para a formação e o desenvolvimento de trabalhadores para o setor e dá outras providências. Brasília: Ministério da Saúde, 2004 b.

BRASIL. Ministério da Saúde. Secretaria de Gestão do Trabalho e da Educação na Saúde. Departamento de Gestão da Educação em Saúde. Politica Nacional de Educação Permanente em Saúde. Brasília: Ministério da 
Saúde, 2009. 64p. (Série B Textos Básicos de Saúde; Série Pactos Pela Saúde, v. 9, 2009).

BRUM, Liege M. A pedagogia da roda como dispositivo de educação permanente na enfermagem hospitalar: estudo de uma experiência educativa na perspectiva da integralidade. 132 f. Dissertação (Mestrado em Enfermagem) - Universidade Federal do Rio Grande do Sul, Porto Alegre, 2009.

CARVALHO, Yara M.; CECCIM, Ricardo B. Formação e educação em saúde: aprendizados com a saúde coletiva. In: CAMPOS, Gastão W. et al. (orgs.). Tratado de saúde coletiva. São Paulo: Hucitec, 2006. p. 149-182.

CECCIM, Ricardo B. Trabalho, educação e formação na integralidade do cuidado: processos de trabalho e de ensino nas práticas cotidianas em saúde. In: PINHEIRO, Roseni; MATTOS, Rubem A. (orgs.). Cuidado: as fronteiras da integralidade. São Paulo, Rio de Janeiro: Hucitec; Abrasco, 2004. p. 259-278.

CECCIM, Ricardo B. Educação permanente em saúde: desafio ambicioso e necessário. Interface: Comunicação, Saúde, Educação, Botucatu, v. 9, n. 16, p. 161-177, 2005.

CECCIM, Ricardo B.; FERLA, Alcindo A. Educação e saúde: ensino e cidadania como travessia de fronteiras. Trabalho, Educação e Saúde, Rio de Janeiro, v. 6, n. 3, p. 443456, 2009.

COLOMÉ, Juliana S. A formação de educadores em saúde na graduação em enfermagem: concepções dos graduandos. 130f. Dissertação (Mestrado em Enfermagem) - Universidade Federal do Rio Grande do Sul, Porto Alegre, 2007.

DAVINI, Maria C. Enfoques, problemas e perspectivas na educação permanente dos recursos humanos de saúde. In: BRASIL. Ministério da Saúde. Secretaria de Gestão do Trabalho e da Educação na Saúde. Departamento de Gestão da Educação em Saúde. Política Nacional de Educação Permanente. Brasília: Ministério da Saúde, 2009. p. 39-58.
DIAS, Cláudia A. Grupo focal: técnica de coleta de dados em pesquisas qualitativas. Informação \& Sociedade: estudos, João Pessoa, v. 10, p. 1-12, 2000.

FAUSTINO, Regina H.; EGRY, Emiko. A formação da enfermeira na perspectiva da educação: reflexões e desafios para o futuro. Revista da Escola de Enfermagem da USP, São Paulo, v. 36, n. 4, p. 332-337, 2002.

FLORES, Giovana E. Educação permanente e aprendizagem significativa no contexto hospitalar: a perspectiva de enfermeiras educadoras. 115 fls. Dissertação (Mestrado em Enfermagem) - Universidade Federal do Rio Grande do Sul (UFRGS), Porto Alegre, 2011.

FURTER, Pierre. Educação e reflexão. Rio de Janeiro: Vozes, 1985.

GEOVANINI, Telma et al. História da Enfermagem: versões e interpretações. Rio de Janeiro: Revinter, 2010.

ITO, Elaine E. et al. O ensino de enfermagem e as diretrizes curriculares nacionais: utopia $\mathrm{x}$ realidade. Revista da Escola de Enfermagem da USP, São Paulo, v. 40, n. 4, p. 570-575, 2006.

KASTRUP, Virgínia. Aprendizagem, arte e invenção. Psicologia em Estudo, Maringá, v. 6, n. 1, p. 17-27, jan.- jun. 2001.

KRUEGER, Richard. Focus groups: a practical guide for applied research. Newbury Park (CA): Sage, 1988.

KRUSE, Maria H. Os poderes dos corpos frios: das coisas que se ensinam às enfermeiras. Brasília: Associação Brasileira de Enfermagem, 2004.

LOPES, Elisabeth F. A formação das profesoras enfermeiras da Escola Técnica de Enfermagem do Hospital de Clínicas de Porto Alegre e suas práticas educativas. $265 \mathrm{f}$. Dissertação (Mestrado em Educação) - Universidade Federal do Rio Grande do Sul, Porto Alegre, 2007.

MINAYO, Maria Cecília S. O desafio do conhecimento: pesquisa qualitativa em saúde. São Paulo: Hucitec, 2006. 
ROSCHKE, Maria A. Aprendizagem e conhecimento significativo nos serviços de saúde. Washington: OPS/OMS, 1997.

SENA, Roseni R.; RICALDONI, Carlos A. C. Educação permanente: uma ferramenta para pensar e agir no trabalho de enfermagem. Revista Latino-Americana de Enfermagem, Ribeirão Preto, v. 14, n. 6, p. 837-842, 2006.

SILVA, Kênia L. et al. Educação em enfermagem e os desafios para a promoção da saúde. Revista Brasileira de Enfermagem, Brasília, v. 62, n. 1, p. 86-91, jan.-fev. 2009.

SILVA, Mara N.; CONTE, Marta; VIAL, Sandra R. M. Educação permanente em ato. In: ESCOLA de Saúde Pública/ESP/RS, Escola de Saúde Pública (eds.). A política de educação permanente em saúde: a trajetória no Rio Grande do Sul. Porto Alegre: ESP/RS, 2008. p. 7-20.
STROSCHEIN, Karina A.; MACHADO, Maria E. Educação permanente nos serviços de saúde: um estudo sobre as experiências realizadas no Estado do Rio Grande do Sul. In: ESCOLA de Saúde Pública - ESP/RS, Escola de Saúde Pública (eds.). A politica de educação permanente em saúde: a trajetória no Rio Grande do Sul. Porto Alegre: ESP/RS, 2009. p. 64-91.

TEIXEIRA, Alex N. Análise qualitativa com o programa NVivo 8: fundamentos. São Paulo: Consultoria NVivo no Brasil, 2010.

TRAD, Leny B. Grupos focais: conceitos, procedimentos e reflexões baseadas em experiências com o uso da técnica em pesquisas de saúde. Physis: Revista de Saúde Coletiva [on line], Rio de Janeiro, v. 19, n. 3, p. 777-796, 2009.

Recebido em 07/11/2013

Aprovado em 13/10/2014 